\title{
Identification of a novel potential antitumor activity of gossypol as an APEI/Ref-I inhibitor
}

\author{
This article was published in the following Dove Press journal: \\ Drug Design, Development and Therapy \\ 9 May 2014 \\ Number of times this article has been viewed
}

\section{Chengyuan Qian \\ Mengxia Li \\ Jiangdong Sui \\ Tao Ren \\ Zheng $\mathrm{Li}$ \\ Liang Zhang \\ Liwei Zhou \\ Yi Cheng \\ Dong Wang}

Cancer Center, Daping Hospital and Research Institute of Surgery,

Third Military Medical University,

Chongqing, People's Republic of China

Correspondence: Dong Wang

Cancer Center, Daping Hospital and Research Institute of Surgery, Third

Military Medical University, 10 Changjiang

Zhi road, Yuzhong District, Chongqing

400042, People's Republic of China

Email dongwang64@hotmail.com

\begin{abstract}
The human apurinic/apyrimidinic endonuclease 1/redox enhancing factor-1 (APE1/Ref-1), an essential multifunctional protein involved in the repair of oxidative deoxyribonucleic acid (DNA) damage and transcriptional regulation, is often overexpressed in tumor tissues and cancer cells. Moreover, APE1/Ref-1 (APE1) overexpression has been linked to chemoresistance in human tumors. Thus, inhibiting APE1 function in cancer cells is considered a promising strategy to overcome resistance to therapeutic agents. Gossypol is a Bcl-2 homology 3 (BH3)-mimetic agent and is able to bind to the $\mathrm{BH} 3$ domain of $\mathrm{B}$-cell lymphoma 2 (Bcl-2) family members. Other studies demonstrated that $\mathrm{Bcl}-2$ directly interacted with $\mathrm{APE} 1$ via its $\mathrm{BH}$ domains. Using apurinic/ apyrimidinic (AP) endonuclease assays, we found that gossypol inhibits the repair activity of APE1. Electrophoretic mobility shift assays and dual luciferase assays showed that gossypol could also inhibit the redox function of APE1. Using dual polarization interferometry technology, we show that gossypol can directly interact with APE1. Furthermore, addition of gossypol, in conjunction with APE1 overexpression, leads to cancer cell death. The addition of gossypol also enhances the cell killing effect of the laboratory alkylating agent methyl methanesulfonate and the clinical agent cisplatin (DDP). Administration of gossypol significantly inhibited the growth of xenografts. Furthermore, the combined treatment of gossypol and DDP resulted in a statistically higher antitumor activity compared with DDP alone in vivo. In conclusion, we have demonstrated that gossypol effectively inhibits the repair and redox activity of APE1 through a direct interaction.
\end{abstract}

Keywords: cancer, oxidative DNA damage, BH3-mimetic

\section{Introduction}

The multifunctional enzyme apurinic/apyrimidinic endonuclease 1/redox enhancing factor-1 (APE1/Ref-1, referred to from hereon as APE1) is a vital protein that acts as an essential master regulator of oxidative deoxyribonucleic acid (DNA) damage repair, contributing to the maintenance of genome stability. After it was cloned by two independent groups in 1991 as a DNA repair enzyme first and as a redox protein the following year, APE1 has been described as playing a role in several biological contexts. ${ }^{1-3}$ APE1 is the major apurinic/apyrimidinic endonuclease of the base excision repair (BER) pathway and repairs apurinic/apyrimidinic (AP) sites throughout the genome. More recently, there is mounting evidence that DNA repair is an effective target for improving anticancer treatment paradigms using DNA-interactive cytotoxins. ${ }^{4}$ APE1 redox activity was initially identified when it was shown to reduce the transcription factor activator protein-1 (AP-1), thus enhancing its DNA-binding activity. ${ }^{1,5}$ APE1 maintains a number of transcription factors, such as nuclear factor- $\mathrm{KB}(\mathrm{NF}-\kappa \mathrm{B}), \mathrm{AP}-1$, and p53, in their active, reduced state, thereby influencing gene expression and maintaining 
genomic stability. ${ }^{6}$ Emerging studies continue to add to the different activities of APE1. Its redox regulation influences stress responses, DNA repair, and other cellular functions, including angiogenesis, inflammation, and cell survival.

APE1 is often overexpressed in tumor tissues and cancer cells of diverse origin, such as germ cell tumors, osteosarcomas, hepatocellular carcinomas, multiple myelomas, and pancreatic, breast, prostate, ovarian, cervical, and non-small-cell lung cancers. ${ }^{7-17}$ High APE1 expression is associated with chemo- and radiotherapy resistance, poor outcome, incomplete therapeutic responses, shorter relapsefree intervals, shorter survival times, and accelerated angiogenesis. ${ }^{18-20}$ Targeted knockdown or functional impairment of APE1 in mammalian cells enhances apoptosis, inhibits cell proliferation, and sensitizes cells to a variety of genotoxic agents (eg, methyl methanesulfonate [MMS], $\mathrm{H}_{2} \mathrm{O}_{2}$, temozolomide, etoposide, cisplatin [DDP], and doxorubicin). ${ }^{21}$

APE1 thus represents a promising therapeutic target in different mechanistic contexts. Inhibitors that affect the BER function of APE1 can be utilized as a complementary treatment option for those patients encountering resistance to DNA-damaging agents. Alternatively, chemically blocking the redox function of APE1 via selective inhibition in cancer cells might interfere with regulation of transcription and alter a number of stress-induced responses of cancer cells. ${ }^{22}$ Recent data indicate that blocking the repair function of APE1 leads to cell death, while redox activity inhibition leads to decreased cell growth and cytostatic effects. ${ }^{19}$ Due to the dual functions of APE1, several inhibitors have been discovered that selectively inhibit either its DNA repair or redox function. DNA repair inhibitors include the indirect inhibitor methoxamine and the direct/indirect inhibitors such as lucanthone and CRT0044876. ${ }^{23}$ The redox function inhibitors are soy isoflavones, resveratrol, ${ }^{24} \mathrm{E} 3330,{ }^{25,26}$ and its benzoquinone and naphthoquinone analogs. ${ }^{27}$
Gossypol is a yellow compound extracted from the cotton plant and tropical trees (Figure 1). Gossypol is a potent antifertility agent in males ${ }^{28}$ and inhibits the proliferation of many human cancer cells in vitro and in vivo. ${ }^{29-31}$ However, a detailed mechanism by which proliferation inhibition occurs, remains to be elucidated. Existing literature shows that gossypol exerts its pharmacological actions, either therapeutic or toxic, by an interaction with biomolecular targets such as enzymes, signal transduction mediators and membranes. ${ }^{32}$ Through the study of these interactions, potential therapeutic exploitations of gossypol can be explored. The mechanism of gossypol's apoptotic effect involves the inhibition of the antiapoptotic B-cell lymphoma 2 (Bcl-2) family members and interaction with the mitochondrial caspase pathways. Gossypol is a Bcl-2 homology 3 (BH3)mimetic agent, and is able to bind to the $\mathrm{BH} 3$ domain of the antiapoptotic proteins B-cell lymphoma-extra large (Bcl-xl) and Bcl-2 and antagonize their effect. ${ }^{33}$ Zhao et $\mathrm{ll}^{34}$ found that Bcl-2 directly interacted with APE1 via its $\mathrm{BH}$ domains.

Because gossypol has been shown to function as a BH3mimetic agent enhancer and Bcl-2 directly interacts with APE1 via its BH domains, we undertook a series of studies to determine whether gossypol was able to inhibit APE1 activity and thereby enhance the cytotoxic effects of alkylating agents. We describe here that gossypol is an inhibitor of APE1 that effectively abolished both the repair and redox activity of APE1 through a direct interaction. Importantly, when in combination with APE1 overexpression, gossypol kills cancer cells more effectively, and addition of gossypol enhances the cell-killing effect of the laboratory alkylating agent MMS and the clinically relevant agent DDP.

\section{Materials and methods Materials}

Gossypol and myricetin were purchased from Sigma-Aldrich (St Louis, MO, USA), dissolved in 100\% dimethyl sulfoxide, and

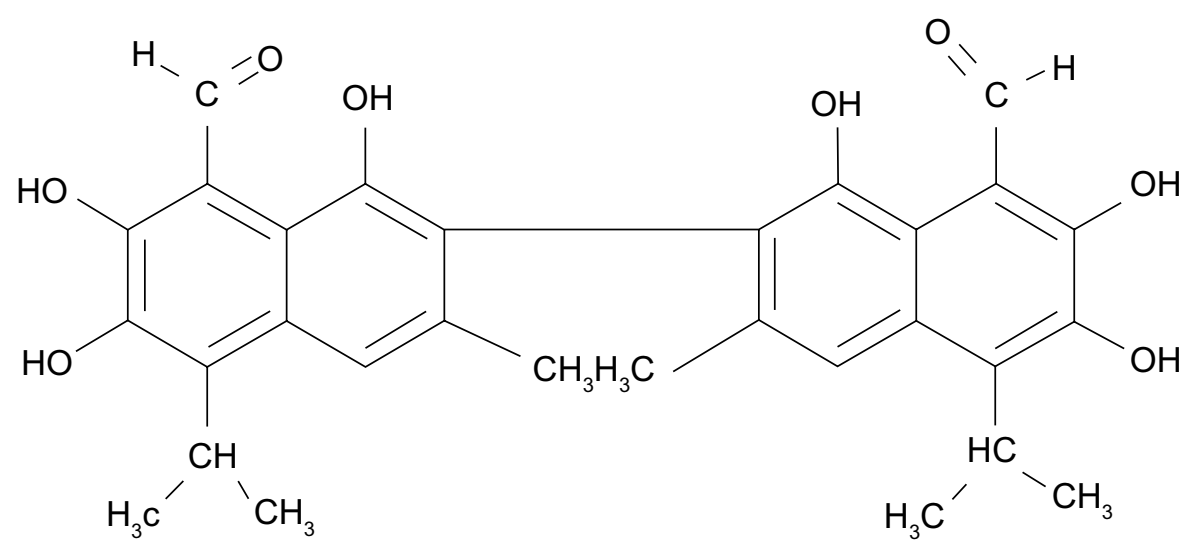

Figure I Structure of gossypol. 
stored as $10 \mathrm{mM}$ stocks at $-20^{\circ} \mathrm{C}$. Dulbecco's Modified Eagle's Medium (DMEM), fetal bovine serum (FBS), and trypsin were obtained from GE Healthcare Life Sciences (Logan, UT, USA). A LightShift chemiluminescence electrophoretic mobility shift assay (EMSA) kit was purchased from Thermo Fisher Scientific (Rockford, IL, USA). The luciferase-harboring vector (pGL3)-control vector, thymidine kinase-driven Renilla luciferase (pRL-TK) vector, Dual-Luciferase Assay System kit, T4 polynucleotide kinase, T4 ligase, restriction endonucleases, and high-fidelity Pyrococcus furiosis DNA polymerase were from Promega (Madison, WI, USA). A Cell Counting Kit-8 (CCK-8) was purchased from Beyotime Institute of Biotechnology (Shanghai, People's Republic of China).

\section{Cell culture}

HeLa (human cervical cancer cell line), A549 (human lung cancer cell line), and HepG2 (human liver hepatocellular carcinoma cell line) cell lines were purchased from the American Type Culture Collection (Manassas, VA, USA) and cultured in DMEM supplemented with 10\% (volume/volume [v/v]) heat-inactivated FBS, $100 \mathrm{U} / \mathrm{mL}$ penicillin and $100 \mu \mathrm{g} / \mathrm{mL}$ streptomycin in a humidified 5\% $\mathrm{CO}_{2} / 95 \%$ air incubator at $37^{\circ} \mathrm{C}$. Redox-deficient mutant APE1-reconstituted HeLa cell lines, APE1 ${ }^{\mathrm{C} 65 \mathrm{~S}}$, were developed as described previously. ${ }^{35}$ Cell lines stably expressing high levels of APE1 were generated using a pCDH-APE1 expression plasmid. Plasmids were transfected into HeLa cells, and stable cell lines were established by selection with $10 \mu \mathrm{g} / \mathrm{mL}$ puromycin.

\section{AP endonuclease assays}

To test inhibition of AP endonucleases by gossypol, an oligonucleotide cleavage assay designed to monitor the cleavage of substrate to product through electrophoretic separation was utilized..$^{36}$ Briefly, a 42-mer oligonucleotide containing a tetrahydrofuran site at the 20th position, the analog of an abasic site, was $5^{\prime}$-end labeled with 32P. The labeling reaction consisted of $10 \mathrm{pmol}$ of the single-stranded oligonucleotide, $2.5 \mathrm{pmol}$ of $\gamma$-32P-ATP, T4 polynucleotide kinase, and the appropriate kinase buffer in a total volume of $10 \mu \mathrm{L}$, and was incubated for 30 minutes at $37^{\circ} \mathrm{C}$ and 5 minutes at $95^{\circ} \mathrm{C}$. Complementary oligonucleotide was then added at $22^{\circ} \mathrm{C}$ to form duplex DNA. Activity assays contained 0.5 pmol of labeled duplex oligonucleotide, $1 \times$ REC buffer $(50 \mathrm{mM}$ HEPES, $50 \mathrm{mM} \mathrm{KCl}$, $10 \mathrm{mM} \mathrm{MgCl}, 1 \%$ [weight/volume $\{\mathrm{w} / \mathrm{v}\}$ ] bovine serum albumin, $0.05 \%[\mathrm{v} / \mathrm{v}]$ Triton $\mathrm{X}-100[\mathrm{pH} 7.5]$ ), and APE1 (0 to $10 \mu \mathrm{g}$ ) in a $10 \mu \mathrm{L}$ reaction volume and were incubated at $37^{\circ} \mathrm{C}$ for 15 minutes. The reactions were terminated by adding $10 \mu \mathrm{L}$ formamide without dyes. Equal volumes $(20 \mu \mathrm{L})$ of the reaction products from the AP endonuclease activity assay were resolved on a $20 \%$ polyacrylamide gel with $7 \mathrm{M}$ urea in $1 \times$ Tris-borate ethylenediaminetetraacetic acid (EDTA) buffer at $300 \mathrm{~V}$ for 40 minutes. Wet gels were autoradiographed at $-70^{\circ} \mathrm{C}$ overnight.

\section{APEI-DNA binding assay}

APE1-DNA binding experiments were performed as described previously, with slight modifications. ${ }^{37}$ Briefly, to elucidate whether gossypol could inhibit APE1 by interfering with the APE1-DNA interaction through its DNA intercalation ability, we measured the DNA-binding capacity of APE1 in the presence of gossypol by incubating different concentrations of gossypol $(10 \mu \mathrm{M}$ and $100 \mu \mathrm{M})$ with $30 \mathrm{ng}$ of purified human APE1 protein at room temperature for 30 minutes in $25 \mathrm{mM} 3-(\mathrm{N}-\mathrm{mor}-$ pholino)propanesulfonic acid (MOPS)-KOH, pH 7.2, $100 \mathrm{mM}$ $\mathrm{KCl}, 10 \%$ glycerol, $1 \mathrm{mM}$ DL-Dithiothreitol, $50 \mu \mathrm{g} / \mathrm{mL}$ bovine serum albumin, and $4 \mathrm{mM}$ EDTA. Incubations were then mixed with 0.1 pmol 32P-radiolabeled oligonucleotide (Midland Certified Reagent Co, Midland, TX, USA) on ice for 5 minutes. Binding reactions were resolved on a nondenaturing polyacrylamide gel (20 mM Tris- $\mathrm{HCl}, \mathrm{pH} 7.5,10 \mathrm{mM}$ sodium acetate, $0.5 \mathrm{mM}$ EDTA, $8 \%$ acrylamide, $2.5 \%$ glycerol) in 20 mM Tris- $\mathrm{HCl}, \mathrm{pH} 7.5,10 \mathrm{mM}$ sodium acetate, $\mathrm{pH} 7.5,0.5 \mathrm{mM}$ EDTA, and electrophoresis was performed at $4^{\circ} \mathrm{C}$ for 2 hours at $120 \mathrm{~V}$. The gel was dried and autoradiographed to identify the location of bound and unbound DNA.

\section{EMSA}

Experiments were performed according to the manufacturer's instructions from the LightShift chemiluminescence EMSA kit (Thermo Fisher Scientific), with minor modifications. Briefly, the nuclear extracts were incubated with 3'-biotinlabeled and purified double-stranded oligonucleotide probes containing consensus sequences for NF- $\kappa \mathrm{B}$ binding sites (Invitrogen, Shanghai, People's republic of China). After incubation, the samples were separated on a $5 \%$ polyacrylamide gel at $100 \mathrm{~V}$ for 1 hour and then transferred to a Zeta-Probe GT nylon membrane (Bio-Rad Laboratories, Hercules, CA, USA). The probes were detected by horse radish peroxidase (HRP)-conjugated streptavidin (1:300) and the bands were visualized by electrochemiluminescence reagents provided with the kit. The resultant bands were quantified using Quantity One imaging software (Bio-Rad Laboratories).

\section{Dual luciferase assays}

HeLa cells were seeded into 24-well plates in Dulbecco's Modified Eagle's Medium with 10\% FBS and then cotransfected with $800 \mathrm{ng}$ of NF- $\mathrm{KB}$ luciferase (Luc) or 
AP-1 Luc (luciferase gene with the NF- $\mathrm{BB}-$ responsive or AP-1-responsive promoter) (Beyotime Institute of Biotechnology) and $40 \mathrm{ng}$ of pRL-TK, using Lipofectamine 2000 (Invitrogen, Carlsbad, CA, USA) according to the manufacturer's protocol. Transfections were done in triplicate, and after 48 hours cells were treated with gossypol ( 0 , $25,50 \mu \mathrm{M}$ ) for 24 hours. Luciferase assays were carried out using the Dual-Luciferase Reporter Assay System (Promega) according to the manufacturer's instructions. Luciferase activity was measured by a Monolight 2010 luminometer (Analytical Luminescence Laboratory, San Diego, CA, USA). Sample values were normalized to Renilla luciferase (Promega). Values shown are the averages and standard error from three independent experiments.

\section{Dual polarization interferometry}

Interactions between gossypol and APE1 were investigated using the dual polarization interferometry (DPI) technique with an AnaLight Bio200 (Farfield Scientific, Crew, UK). This instrument has been described in detail previously. ${ }^{38,39}$ Briefly, APE1 was immobilized on the surface of unmodified chips on different channels at a concentration of $0.1 \mathrm{mg} / \mathrm{mL}$ in running buffer containing $20 \mathrm{mM}$ HEPES (pH 7.4), $100 \mathrm{mM}$ $\mathrm{NaCl}$, and $1 \mathrm{mM} \mathrm{MgCl}$. Gossypol was injected at different concentrations in the same buffer. The dissociation constant value was calculated from curve fitting over the early association phase from three independent experiments.

\section{Cell viability assay}

Cell viability was determined using CCK-8 dye according to the manufacturer's instructions. Briefly, $5 \times 10^{3}$ cells/well were seeded in a 96 -well flat-bottomed plate, grown at $37^{\circ} \mathrm{C}$ for 24 hours, and then placed in serum-starved conditions for a further 6 hours. Subsequently, cells were treated with gossypol at increasing concentrations in the presence of $10 \%$ FBS for 72 hours. After $10 \%$ CCK-8 dye was add to each well, cells were incubated at $37^{\circ} \mathrm{C}$ for 2 hours and the absorbance was determined at $450 \mathrm{~nm}$ using a microplate reader (Bio-Rad Laboratories).

\section{Xenograft assays}

Athymic nude mice, 4-6 weeks of age, were purchased from Beijing Laboratory Animal Research Center (Beijing, People's Republic of China). Animal experiments were approved by Third Military Medical University Guidelines for Use and Care of Animals. HeLa cells $\left(1 \times 10^{7}\right.$ in $100 \mu \mathrm{L}$ phosphate buffered saline) were injected subcutaneously near the left subaxillary area of the nude mice. When tumors reached an appropriate size $\left(200-250 \mathrm{~mm}^{3}\right)$, the mice were randomized into four groups with three mice in each group according to tumor volumes and body weights for the following treatments: vehicle control, gossypol (35 mg/kg/day, per os daily for 2 weeks), DDP ( $4 \mathrm{mg} / \mathrm{kg}$, intraperitoneal injection, twice per week for 2 weeks), and the combination of gossypol and DDP. Tumors were determined by a caliper every 3 days, and the tumor volume was calculated using the formula $V=1 / 2$ (width ${ }^{2} \times$ length). Body weights were also recorded every 3 days. Mice were killed by cervical dislocation after 20 days of drug exposure.

\section{Statistical analysis}

An unpaired Student's $t$ test or analysis of variance with the Bonferroni post hoc test (SPSS software 13.0; IBM Corporation, Armonk, NY, USA) was used for statistical comparison. Statistical tests and $P$ values were two-sided. A $P$-value $<0.05$ was set as the threshold for statistical significance.

\section{Results \\ Gossypol inhibits APEI endonuclease activity and APEI/AP site interaction}

APE1 is the major BERAP endonuclease and comprises $95 \%$ of the total AP endonuclease activity in mammals. ${ }^{40}$ We examined whether gossypol inhibited APE1 endonuclease activity in vitro, using a 42 bp double-stranded DNA oligonucleotide substrate with a tetrahydrofuran abasic site analog at position 20 (Figure 2A). In this assay, APE1-mediated cleavage of the AP site generates a 20-mer 32P-end-labeled product that can be separated from uncleaved substrate on a polyacrylamide gel. Myricetin was used as a positive control, as it was previously identified as an APE1 endonuclease activity inhibitor. ${ }^{23}$ In the presence of 300 pg recombinant APE1 protein, gossypol inhibited APE1 endonuclease activity starting at $0.001 \mu \mathrm{M}$, with a half maximal inhibitory concentration (IC50) of $0.036 \mu \mathrm{M}$. Gossypol inhibition of APE1 was more potent than myricetin (Figure 2B and C). To confirm that this was not an artifact of using recombinant APE1, we performed AP endonuclease activity assays with cellular extract from HeLa cells. Preincubation of gossypol with APE1 protein prior to addition of substrate DNA resulted in a significant reduction in the DNA-binding capacity of APE1 (Figure 2D). Gossypol also inhibited AP site cleavage directed by APE1 in HeLa whole cell extract (Figure 2E).

\section{Gossypol blocks the redox function of APEI in cell-free assays}

EMSAs were used to determine if gossypol could inhibit the redox function of APE1. APE1 affects redox activity through the control of the redox state of the cysteine (Cys) residues 


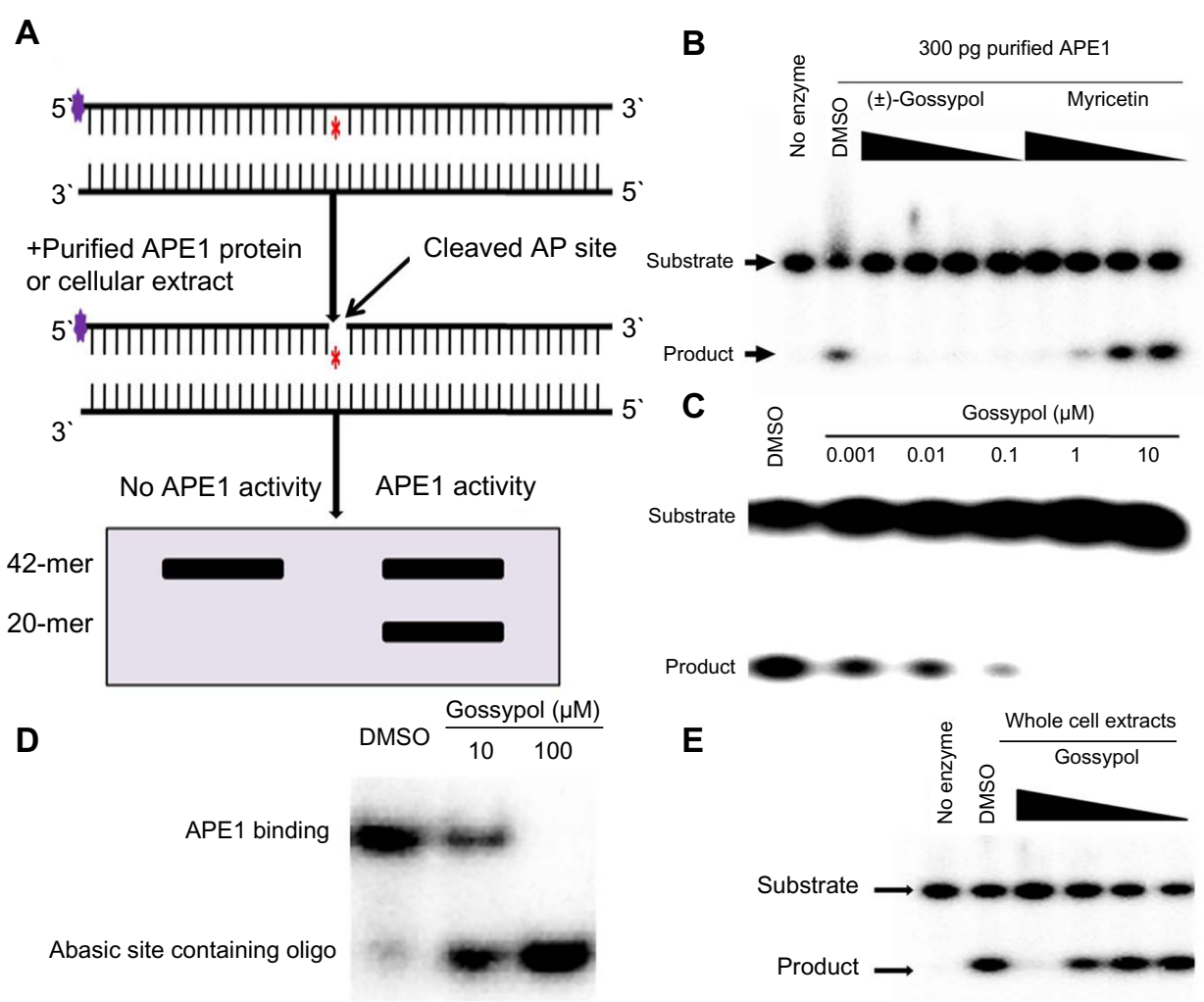

Figure 2 Effect of gossypol on APEI endonuclease activity.

Notes: (A) Schematic for the gel-based AP site cleavage assay. (B) Gossypol dose-dependently inhibited AP site cleavage activity with purified APEI (lane 3-6: I00, I0, I, $0.1 \mu \mathrm{M}$ gossypol; lane 7-10: 100, I0, I, $0.1 \mu \mathrm{M}$ myricetin). (C) Gossypol inhibited AP site cleavage activity with 300 ng purified APEI. (D) Purified APEI protein (30 ng) was exposed to gossypol prior to measuring AP site interaction activity via a radiolabel assay. The upper band indicates APEI-bound AP oligonucleotides while the lower band represents the unbound AP oligonucleotide. (E) Gossypol inhibited AP site cleavage activity in HeLa whole cell extracts (lanes 3-6: I0, I, 0.I, 0.0 I $\mu$ M gossypol).

Abbreviations: AP, apurinic/apyrimidinic; APEI, apurinic/apyrimidinic endonuclease I; DMSO, dimethyl sulfoxide; HeLa, human cervical cancer cell line; oligo, oligonucleotides.

located either in the DNA-binding domains or within regulatory regions of the transcription factor itself. ${ }^{41}$ Mutation of Cys65 has been consistently shown to negatively affect the redox activity of APE $1 .^{42}$ To investigate whether gossypol interferes with APE1-activated transcription factor-DNA binding, we incubated nuclear extracts of APE1-wild type (APE1 ${ }^{\mathrm{WT}}$ ) and APE1 ${ }^{\mathrm{C} 65 \mathrm{~S}}$ HeLa cells with gossypol at different doses and analyzed the outcome by EMSA. The NF- $\mathrm{KB}$ DNA-binding activity of $\mathrm{APE} 1^{\mathrm{WT}}$-containing nuclear extracts was significantly reduced in a dose-dependent manner by direct coincubation with gossypol, whereas inhibition was no longer evident in $\mathrm{APE}{ }^{\mathrm{C} 65 \mathrm{~S}}$-containing nuclear extracts (Figure 3B and C). AP-1 and hypoxia-inducible factor 1-alpha (HIF1- $\alpha$ ) DNA-binding activities in the presence of gossypol are consistent with the NF- $\mathrm{KB}$ results (Figure 3D and E). Taken together, these results suggest that gossypol significantly inhibits APE1 redox activity.

\section{Gossypol blocks APEI redox signaling in cells}

The data presented above suggest that gossypol can potently inhibit APE1 redox function in vitro. However, in order to have general utility as a redox inhibitor of APE1, it was important to confirm that gossypol could block APE1 function in living cells. To determine the effect of gossypol in intact cells, we investigated the ability of gossypol to block APE1 redox activity in a cell-based transactivation assay. In this assay, an NF- $\mathrm{KB} / \mathrm{AP}-1$ binding sequence upstream of a luciferase reporter was stably expressed in HeLa cells. Increasing amounts of gossypol decreased the ability of NF- $\mathrm{KB} / \mathrm{AP}-1$ to bind to the promoter in a dose-dependent manner (Figure 4A and B). The results of this in vitro assay indicate that, in cellular studies, gossypol has the potential to block APE1 redox function.

\section{APEI directly interacts with gossypol}

DPI is a method for characterizing thin molecular films based on the analysis of interference patterns resulting from coherent laser light propagating along two vertically stacked, independent optical waveguides. DPI allows simultaneous determination of thickness and density of a biological layer on a sensing wavelength surface in real time. Detection of protein conformational changes upon 

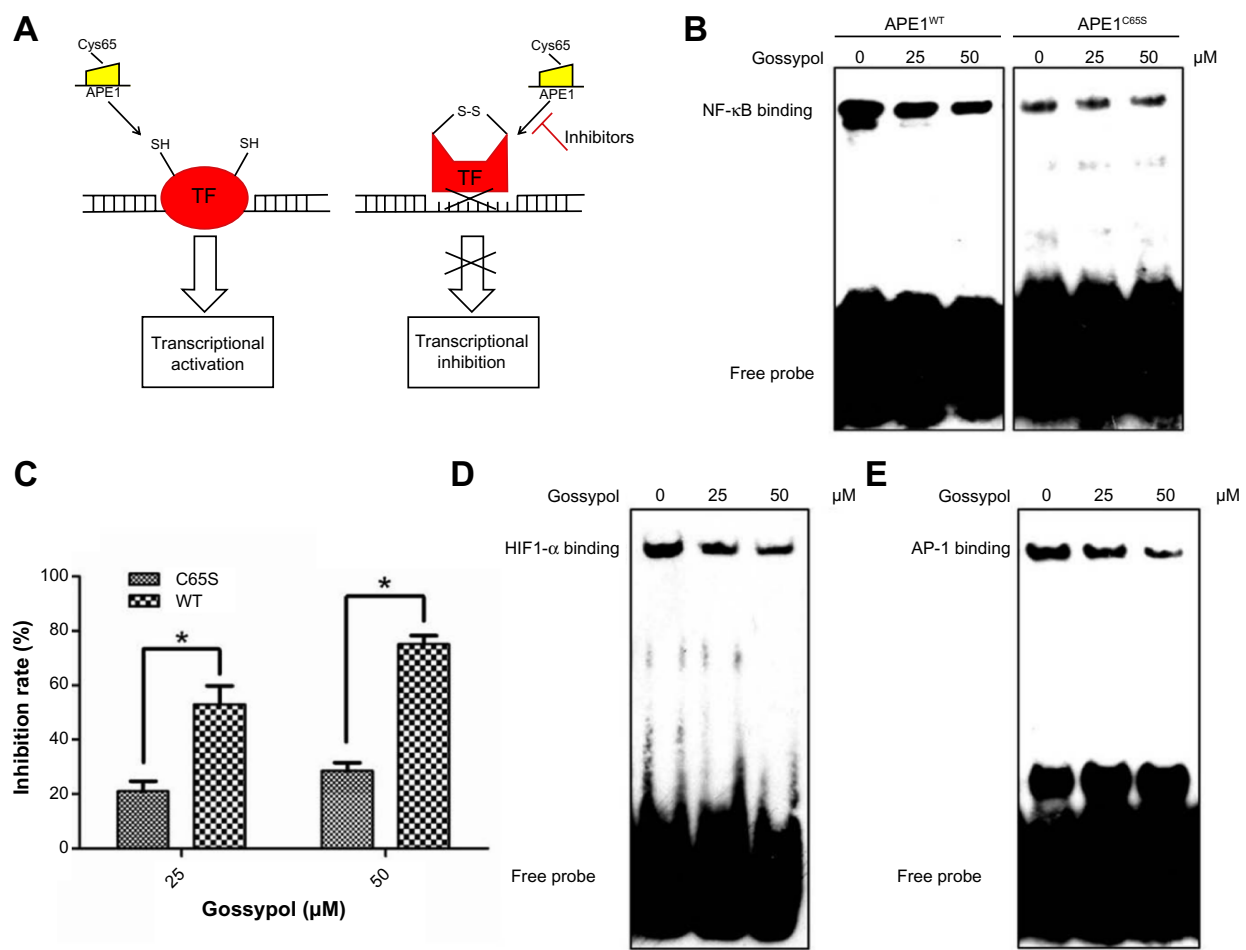

Figure 3 APEI redox function is inhibited by gossypol.

Notes: (A) Scheme for APEI redox signaling activity. APEI interacts with downstream TFs, such as NF- $\mathrm{B}$, AP-I, and HIFI- $\alpha$, converting them from oxidized to reduced states and allowing them to bind to their target promoters and switch on transcription. Cys65 is critical for APEI redox function. (B) Gossypol inhibited NF-KB DNA-binding activities of APEI IT or APEI ${ }^{\mathrm{C} 655}$ HeLa cell nuclear extracts in a dose-dependent manner $(0,25,50 \mu \mathrm{M})$. (C) Quantification of the data from EMSA arrays showing the percentage inhibition of NF-KB DNA-binding activities in APEI ${ }^{W T}$ and APEI ${ }^{C 65 S}$ nuclear extracts after gossypol addition. Each bar represents the mean \pm SD of three experiments. $* P<0.05$. (D) AP-I and (E) HIFI- $\alpha$ DNA-binding activities were inhibited by gossypol in HeLa cell nuclear extracts in a dose-dependent manner (0, $25,50 \mu M)$.

Abbreviations: AP-I, activator protein I; APEI, apurinic/apyrimidinic endonuclease I; APEIC65s, redox-deficient mutant APEI-reconstituted HeLa cell lines; Cys, cysteine; DNA, deoxyribonucleic acid; EMSA, electrophoretic mobility shift assay; HeLa, human cervical cancer cell line; HIFI- $\alpha$, hypoxia-inducible factor I-alpha; NF-KB, nuclear factor- $\mathrm{KB}$; SD, standard deviation; TF, transcription factor; APEI ${ }^{\mathrm{WT}}$, APEI-wild type HeLa cell line.

binding of small molecules using DPI techniques has been reported. ${ }^{38}$ Using DPI, we investigated the binding affinity of APE1 and gossypol. Analysis of the thickness and density of the binding event showed that gossypol was able to bind APE1 (Figure 5A). The kinetic analysis, performed at the early association phase of protein interaction, indicates that the dissociation constant for the APE1-gossypol interaction was $1.40 \mu \mathrm{M}$ (Figure 5B). Our results indicate that gossypol was able to bind with APE1 directly.
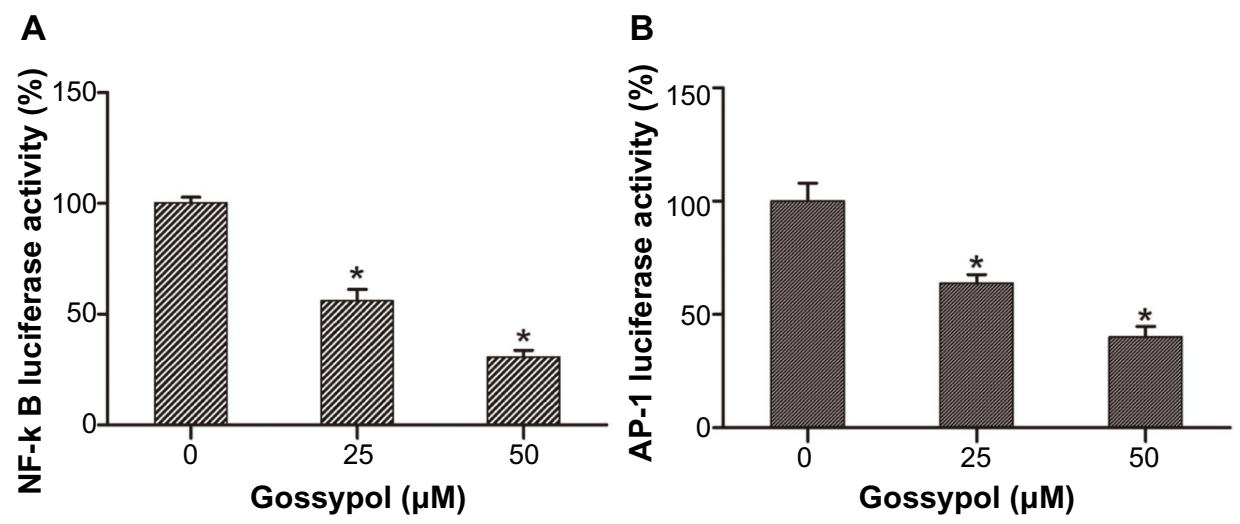

Figure 4 Gossypol inhibited APEI redox activity in a transactivation assay.

Notes: (A) NF-KB-luc and (B) AP-I reporter constructs transfected into HeLa cells were treated with gossypol $(0,25,50 \mu M)$. Each bar represents the mean \pm SD from three independent experiments. $* P<0.05$.

Abbreviations: AP-I, activator protein I; APEI, apurinic/apyrimidinic endonuclease I; HeLa, human cervical cancer cell line; NF- $\mathrm{B}$-luc, nuclear factor- $\mathrm{KB}$ luciferase; $\mathrm{SD}$, standard deviation. 


\section{Effects of gossypol on human cancer cell lines}

The data presented suggest that gossypol can potently and selectively inhibit APE1 in vitro. To further evaluate the biological effect of gossypol, HeLa, HepG2, and A549 cells were treated with increasing concentrations of gossypol for 72 hours, and cell viability was measured with a CCK-8 assay. Gossypol had a cell-growth inhibitory effect on cancer cells (Figure 6A). To determine the role of APE1 in cancer cells treated with gossypol, we generated HeLa cells stably expressing high levels of APE1 using the pCDH-APE1 expression plasmid. In the presence of high APE1 concentrations, gossypol kills cancer cells more effectively than the negative control (Figure 6B). As an additional means of examining the biological potential of the APE1 inhibitors displaying the most promise in the assays above, we evaluated the ability of gossypol to enhance cellular sensitivity to the alkylating agent MMS and the clinically relevant agent, DDP. We determined whether gossypol alone or in combination with alkylating agents had any effect on cell survival, presumably through the inhibition of APE1 repair activity. First, we determined the dose of gossypol that yielded minimal toxicity effects on HeLa cells. As demonstrated in Figure 6A, gossypol reduced the survival of HeLa cells approximately $10 \%$ at a $5 \mu \mathrm{M}$ dose. We then used this dose of gossypol in combination with increasing doses of MMS or DDP (Figure 6C and D). We observed a clear enhancement of cell killing in the presence of gossypol over alkylating agents alone.
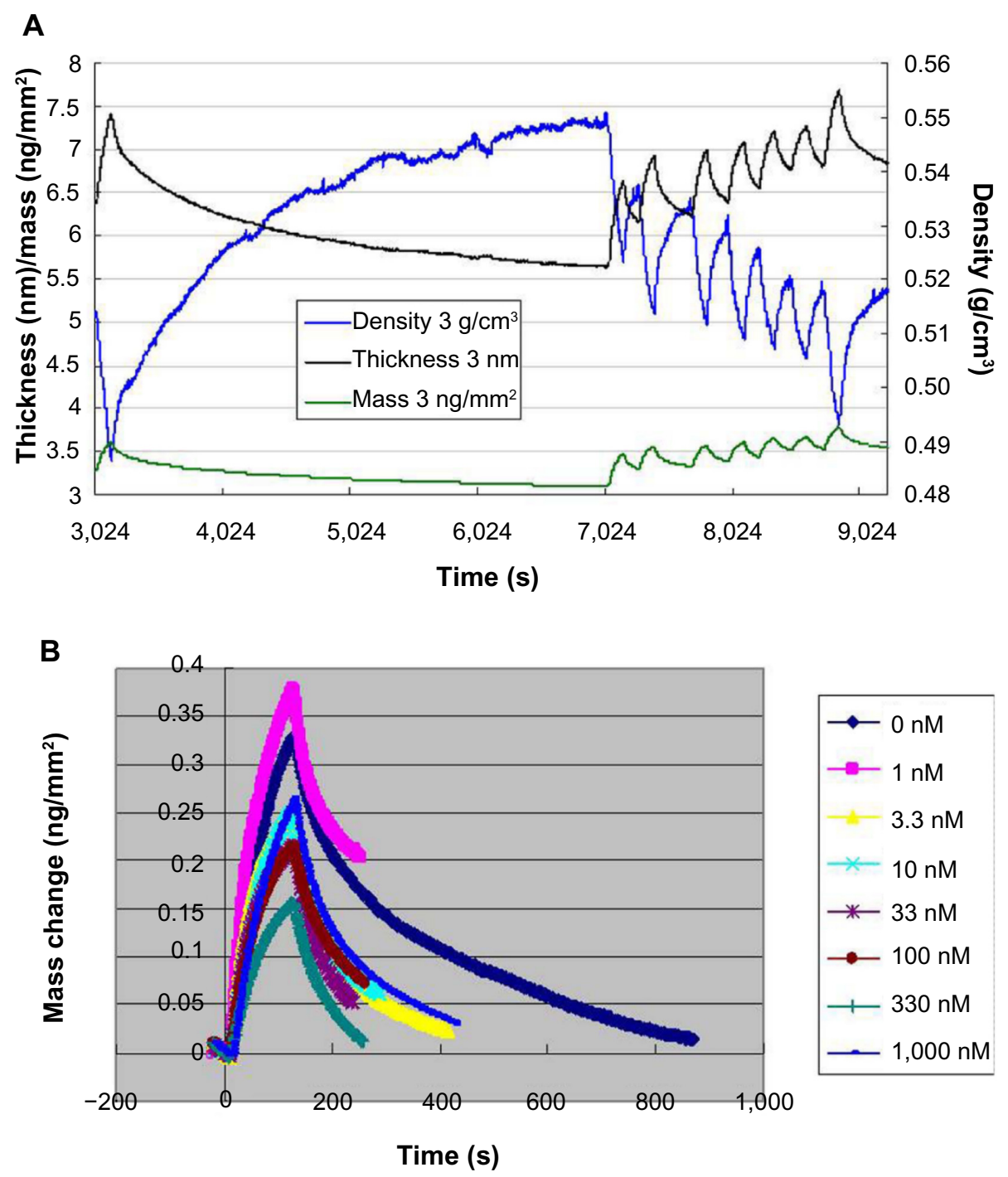

Figure 5 Detection of the binding affinity of APEI and gossypol using DPI.

Notes: (A) Real-time DPI measurements of thickness, mass, and density during the immobilization of APEI and gossypol. (B) Real-time DPI measurements of mass change after gossypol injection at different concentrations.

Abbreviations: APEI, apurinic/apyrimidinic endonuclease I; DPI, dual polarization interferometry; s, seconds. 
A

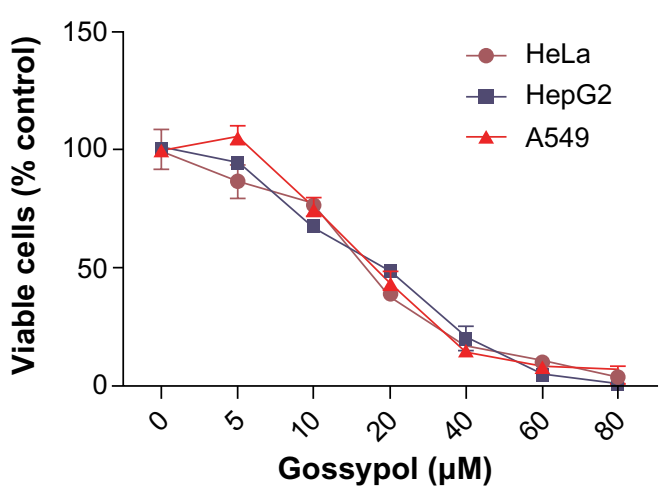

C

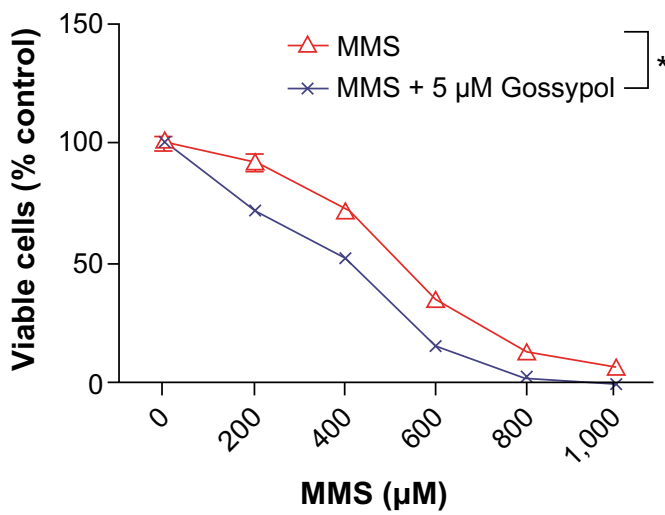

B

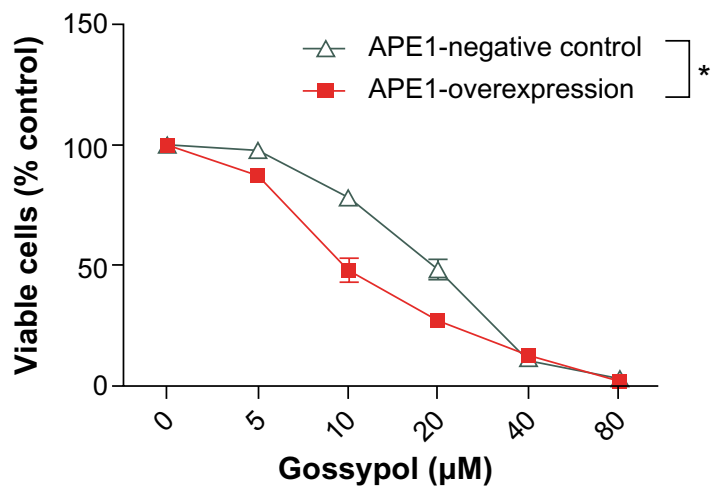

D

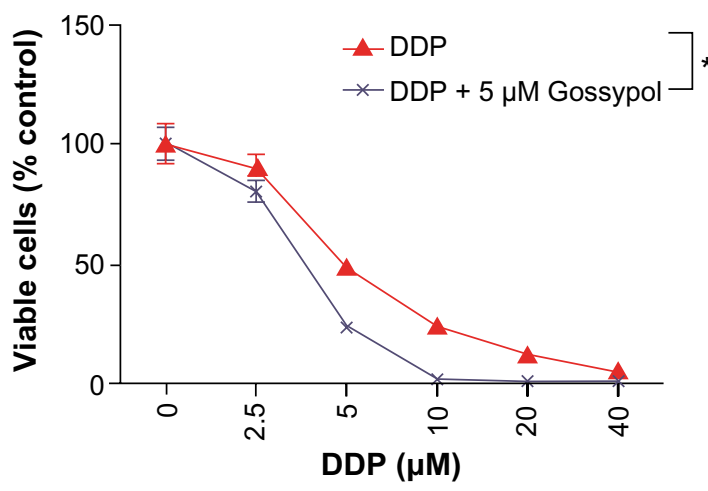

Figure 6 Effect of gossypol on cell survival.

Notes: (A) Cancer cells (HeLa, HepG2, and A549) were treated with increasing doses of gossypol for 72 hours and survival was evaluated using the CCK-8 assay. (B) HeLa cells (APEI negative control and APEI overexpression) were treated with increasing doses of gossypol for 72 hours and survival was determined using the CCK-8 assay. (C) Using a dose of gossypol that caused minimal cell death $(5 \mu \mathrm{M})$, HeLa cells were treated with MMS with or without gossypol. (D) Using a dose of gossypol that caused minimal cell death $(5 \mu \mathrm{M})$, HeLa cells were treated with DDP with or without gossypol. Cell survival percentages were calculated based on the plating efficiency of the untreated cells. Error bars refer to $95 \%$ confidence intervals; $* P<0.001$. A two-tailed ANOVA with Bonferroni post hoc test was used.

Abbreviations: A549, human lung cancer cell line; ANOVA, analysis of variance; APEI, apurinic/apyrimidinic endonuclease I; CCK-8, Cell Counting Kit-8; DDP, cisplatin; HeLa, human cervical cancer cell line; HepG2, human liver hepatocellular carcinoma cell line; MMS, methyl methanesulfonate.

\section{Effects of gossypol on xenograft}

To investigate whether gossypol alone or in combination with the clinically relevant agent DDP can inhibit the tumor in vivo, we tested effects of gossypol on a HeLa xenograft model in athymic nude mice. As shown in Figure 7A-C, differences in tumor growth were significant between the gossypol or DDP alone group and the vehicle control group; the combined treatment of gossypol and DDP had the greatest effect on tumor growth suppression. The animal body weights of the control group and experimental group did not differ significantly throughout the experimental protocol (Figure 7D). Although gossypol had minimal efficacy as a single agent, the combination arm showed the most dramatic tumor response, with a significant delay in the progression of cancer in our xenograft model.

\section{Discussion}

APE1 acts not only as an AP endonuclease but also as a redoxmodifying protein for a diverse array of transcription factors.
Accumulating evidence has implicated APE1 in tumor promotion, progression, and drug resistance, which highlight its potential as a target for new cancer preventive and therapeutic strategies. Because signaling proteins do not act in isolation but rather within an intricate network in the cell, compounds that target multifunctional proteins would not only affect one pathway but would interfere with multiple pathways and their downstream targets. To overcome tumor cell resistance or sensitize tumor cells to currently used but potentially suboptimal chemotherapeutic treatments, we have analyzed the role of APE1 inhibitors as a means of enhancing apoptosis induced by alkylating agents in tumor cells.

Our findings demonstrate that gossypol inhibits the repair activity of APE1 as well as its redox function. Furthermore, using DPI, we found that APE1 directly interacts with gossypol. Our data are preclinical, proof of principle evidence that gossypol targets APE1 and has potent anticancer effects. The results of this study show that gossypol inhibits 
A

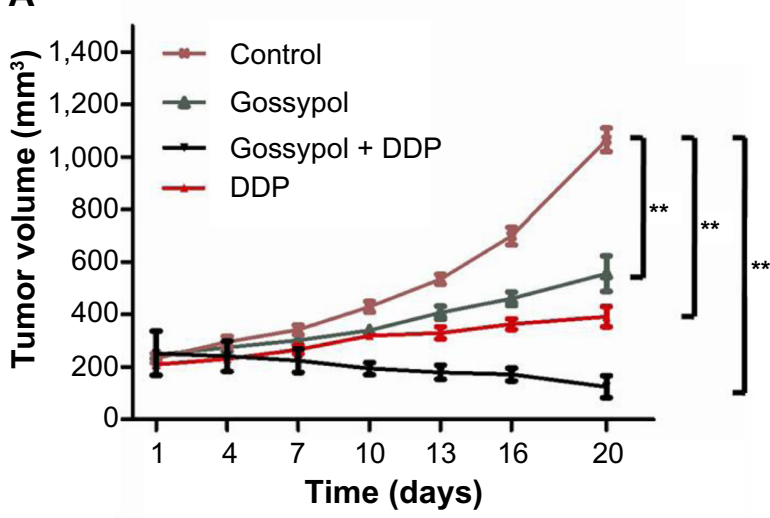

C

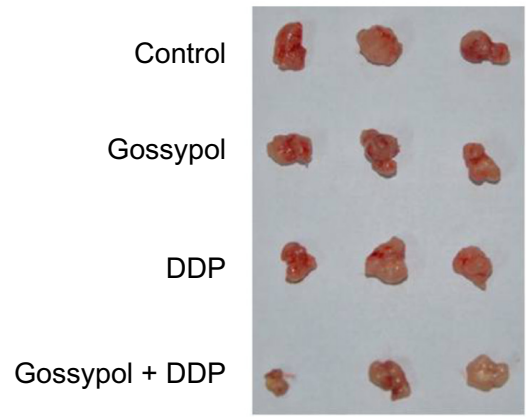

B
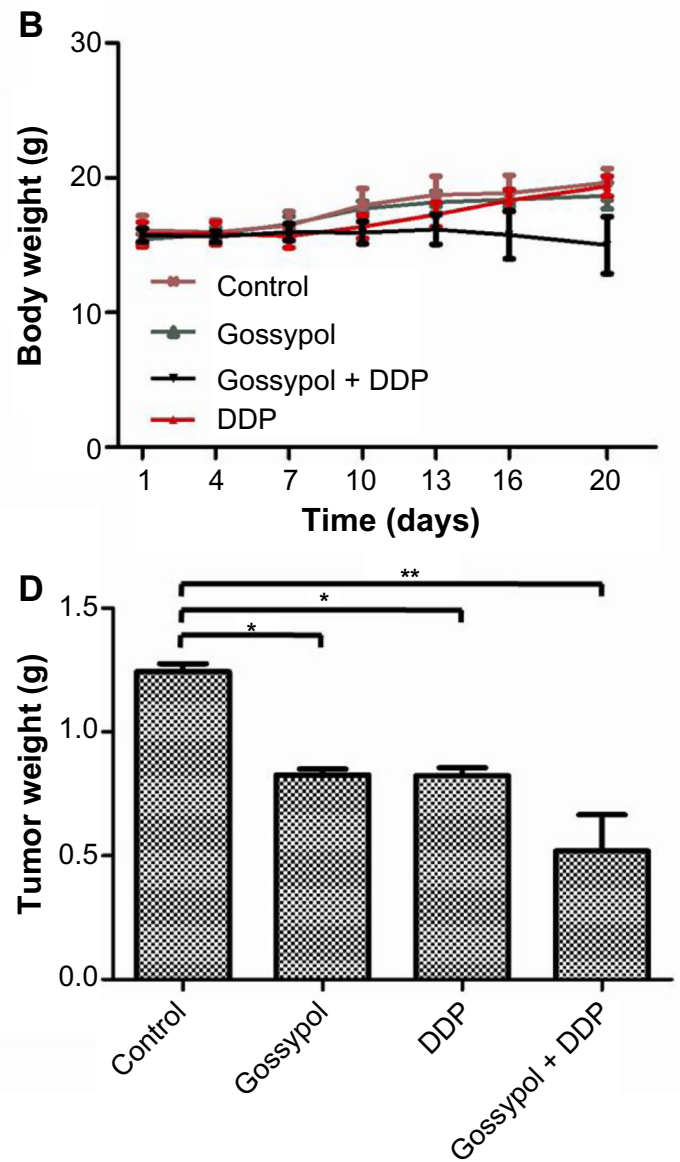

Figure 7 Effect of gossypol on HeLa xenograft tumors.

Notes: (A) Effect of gossypol and/or DDP combination treatments on HeLa xenograft in nude mice. (B) Effect of drug treatments on mouse body weights, as an indicator of toxicity. Statistical analyses of body weight changes showed no significant differences between each experimental group and vehicle-treated group. (C) The xenografts were excised from the mice on day 20. (D) Comparison of the tumor weights in each experimental group on the day when all mice in the control group were killed (day 20). Error bars refer to $95 \%$ confidence intervals. $* P<0.05$; $* * P<0.001$. Two-sided ANOVA with Bonferroni post hoc test was used.

Abbreviations: ANOVA, analysis of variance; DDP, cisplatin; HeLa, human cervical cancer cell line.

not only the repair activity of APE1, but also its redox function. Furthermore, we found that APE1 directly interacts with gossypol using a DPI approach. Given these data, we provide evidence that APE1 is an important anticancer target of gossypol. These findings have significant translational implications. Importantly, gossypol has been shown to inhibit the proliferation of many human cancer cells in vitro and in vivo, and is nontoxic to normal cells and noncancerous cells. $^{31,43,44}$ For instance, studies conducted by three independent laboratories in clinical trials indicate gossypol is apparently safe in doses up to $70 \mathrm{mg} /$ day. ${ }^{45}$

We initially investigated whether gossypol can inhibit the endonuclease activity of APE1 using an oligonucleotide cleavage assay. Targeting DNA repair enzymes in human cells is a more promising strategy for the inhibition of DNA repair during cancer chemotherapy because APE1 performs DNA repair roles in addition to removal of AP sites. The 3'-phosphodiesterase activity of APE1 is important in the protection of cells against the toxic effects of certain agents, such as bleomycin. Indeed, APE1 has been shown to be a predominant contributor to 3'-phosphoglycolate diesterase activity in human cells. ${ }^{46}$ Moreover, the results from the DNA-binding assay demonstrated that gossypol significantly affected the DNA-binding capacity of APE1 (Figure 2D). These studies showed that gossypol strongly inhibited the repair function of APE1.

EMSA results showed that APE1 was involved in nuclear transcription factor (eg, NF- $\kappa \mathrm{B}, \mathrm{AP}-1, \mathrm{HIF} 1-\alpha$, etc, ) DNAbinding complexes and played an important role in maintaining their DNA-binding activities. Our data also showed that nuclear extracts treated with gossypol exhibited reduced transcription factor DNA-binding activities. Reduction/oxidation of specific Cys residues located in the DNA-binding domain of transcription factors represents a fast and efficient way to regulate their activities. Vascotto et $\mathrm{a}^{42,47}$ developed a series of APE1 stable knockdown and knock-in HeLa cell lines. APE1 ${ }^{\mathrm{C} 65 \mathrm{~S}}$, for example, is an APE1 redox-deficient cell line in which the Cys at position 65 was mutated to a serine. 
We exploited these cell lines to determine whether inhibition of redox function by gossypol was specific to APE1 or just a nonspecific inhibitory effect on general transcription factor DNA-binding activities. Our data showed that gos-

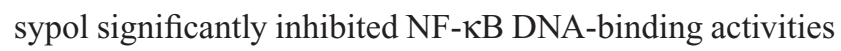
in APE $1^{\text {WT }}$ nuclear extract when compared to the APE1 ${ }^{\mathrm{C} 65 \mathrm{~S}}$ extract (Figure 3). These results suggest that gossypol can potently inhibit APE1 redox function in vitro. Gossypol can also block APE1 redox function in intact cells (Figure 4).

Currently available APE1 inhibitors predominantly inhibit only one of its functions. E3330, for example, inhibits the APE1 redox function, while CRT0044876 blocks its repair function. ${ }^{19,23}$ Importantly, gossypol inhibits both the redox and repair functions of APE1. In order to confirm whether APE1 interacted with gossypol directly, we investigated the binding affinity of APE1 and gossypol using DPI. After binding of gossypol, protein conformational changes were observed (Figure 5). Future analyses will include cocrystallization of APE1 with gossypol or its derivatives in order to develop a synthetic chemistry program aimed at further improving the potency and selectivity of the compounds.

We found that downregulation of APE1 was associated with enhanced cytotoxicity and induction of apoptosis following exposure to alkylating agents, hydrogen peroxide, and other DNA-damaging agents. ${ }^{13}$ This potentiation of cytotoxicity was very similar to the effects of gossypol seen in our study. Co-application of gossypol and the alkylating agents MMS or DDP resulted in an enhancement of cell killing. The growth of HeLa cells xenografts were significantly inhibited by gossypol. Furthermore, the combined treatment of gossypol and DDP resulted in a statistically higher antitumor activity compared with DDP alone, in vivo. These results indicate that gossypol sensitizes DDP induced growth suppression in vivo and suggests that it is a good chemosensitizer candidate to antitumor activity.

Gossypol exerts anticancer activity through a broad effect on cells by regulating $\mathrm{Bcl}-2$ proteins, steroid receptor coactivator (SRC)-1 and SRC-3, activating p53, generating reactive oxygen species and so on. ${ }^{48-51}$ In cancer cells, gossypol selectively reduces the cellular protein concentrations of SRC-1 and SRC-3 without generally altering overall protein expression patterns. ${ }^{51}$ Interestingly, Carrero et al have demonstrated that APE1 can also regulate the activity of SRC-1 by facilitating the recruitment of SRC-1 to HIF $1-\alpha .^{52}$ Our data demonstrate that gossypol inhibits the redox activity of APE1. These data indicate that gossypol can not only inhibit SRC-1 directly but also regulate it indirectly by blocking redox activity of APE1. Moreover, further exploration of new mechanisms will lead to a better understanding of gossypol's biological activity to promote an effective therapeutic exploitation of gossypol. From our initial findings, it is necessary to further develop gossypol as an APE1 inhibitor through structure-function studies to enhance the efficacy of gossypol inhibition of APE1 and, ultimately, tumor sensitization to alkylating agents. Moreover, the addition of gossypol could provide a potent combination for small molecule treatment of tumors receiving alkylation and antiapoptotic therapies.

In conclusion, we have demonstrated that APE1 is a potential molecular target of gossypol, which effectively inhibits both the repair and redox activities of APE1 through a direct interaction. Furthermore, gossypol kills cancer cells more effectively when APE1 is overexpressed. The addition of gossypol also enhanced the cell killing effect of the laboratory alkylating agent MMS and the clinically relevant agent DDP. Given these initial findings, it is necessary to further develop gossypol as an APE1 inhibitor. Through structure-function analyses, the efficiency of gossypol as an APE1 inhibitor can be enhanced, ultimately increasing tumor cell death or sensitization to alkylating agents.

\section{Acknowledgments}

This work was supported by a grant from the National Natural Science Foundation of China (NSFC \#81171904) to Dr Dong Wang.

\section{Disclosure}

The authors declare no conflict of interest in this work.

\section{References}

1. Xanthoudakis S, Curran T. Identification and characterization of Ref-1, a nuclear protein that facilitates AP-1 DNA-binding activity. EMBO J. 1992;11(2):653-665.

2. Robson CN, Hickson ID. Isolation of cDNA clones encoding a human apurinic/apyrimidinic endonuclease that corrects DNA repair and mutagenesis defects in E. coli xth (exonuclease III) mutants. Nucleic Acids Res. 1991;19(20):5519-5523.

3. Demple B, Herman T, Chen DS. Cloning and expression of APE, the cDNA encoding the major human apurinic endonuclease: definition of a family of DNA repair enzymes. Proc Natl Acad Sci U SA. 1991;88(24): 11450-11454.

4. Helleday T, Petermann E, Lundin C, Hodgson B, Sharma RA. DNA repair pathways as targets for cancer therapy. Nat Rev Cancer. 2008;8(3): 193-204.

5. Xanthoudakis S, Curran T. Redox regulation of AP-1: a link between transcription factor signaling and DNA repair. Adv Exp Med Biol. 1996;387:69-75.

6. Tell G, Damante G, Caldwell D, Kelley MR. The intracellular localization of APE1/Ref-1: more than a passive phenomenon? Antioxid Redox Signal. 2005;7(3-4):367-384. 
7. Li Y, Li S, Wu Z, et al. Polymorphisms in genes of APE1, PARP1, and $\mathrm{XRCC} 1$ : risk and prognosis of colorectal cancer in a northeast Chinese population. Med Oncol. 2013;30(2):505.

8. Cun Y, Dai N, Xiong C, et al. Silencing of APE1 enhances sensitivity of human hepatocellular carcinoma cells to radiotherapy in vitro and in a xenograft model. PLoS One. 2013;8(2):e55313.

9. Wu HH, Chu YC, Wang L, et al. Cytoplasmic Ape1 expression elevated by p53 aberration may predict survival and relapse in resected non-small cell lung cancer. Ann Surg Oncol. 2013;20 Suppl 3:S336-S347.

10. Sheng Q, Zhang Y, Wang R, et al. Prognostic significance of APE1 cytoplasmic localization in human epithelial ovarian cancer. Med Oncol. 2012;29(2):1265-1271.

11. Kim JS, Kim JM, Liang ZL, et al. Prognostic significance of human apurinic/apyrimidinic endonuclease (APE/Ref-1) expression in rectal cancer treated with preoperative radiochemotherapy. Int $J$ Radiat Oncol Biol Phys. 2012;82(1):130-137.

12. Qing Y, Yang XQ, Zhong ZY, et al. Microarray analysis of DNA damage repair gene expression profiles in cervical cancer cells radioresistant to 252Cf neutron and X-rays. BMC Cancer. 2010;10:71.

13. Wang D, Luo M, Kelley MR. Human apurinic endonuclease 1 (APE1) expression and prognostic significance in osteosarcoma: enhanced sensitivity of osteosarcoma to DNA damaging agents using silencing RNA APE1 expression inhibition. Mol Cancer Ther. 2004;3(6): 679-686.

14. Al-Attar A, Gossage L, Fareed KR, et al. Human apurinic/apyrimidinic endonuclease (APE1) is a prognostic factor in ovarian, gastro-oesophageal and pancreatico-biliary cancers. Br J Cancer. 2010;102(4): 704-709.

15. Xie JY, Li MX, Xiang DB, et al. Elevated expression of APE1/Ref-1 and its regulation on IL-6 and IL-8 in bone marrow stromal cells of multiple myeloma. Clin Lymphoma Myeloma Leuk. 2010;10(5):385-393.

16. Kelley MR, Cheng L, Foster R, et al. Elevated and altered expression of the multifunctional DNA base excision repair and redox enzyme Ape1/ref-1 in prostate cancer. Clin Cancer Res. 2001;7(4):824-830.

17. Robertson KA, Bullock HA, XuY, et al. Altered expression of Ape1/ref-1 in germ cell tumors and overexpression in NT2 cells confers resistance to bleomycin and radiation. Cancer Res. 2001;61(5):2220-2225.

18. Luo M, He H, Kelley MR, Georgiadis MM. Redox regulation of DNA repair: implications for human health and cancer therapeutic development. Antioxid Redox Signal. 2010;12(11):1247-1269.

19. Luo M, Delaplane S, Jiang A, et al. Role of the multifunctional DNA repair and redox signaling protein Ape1/Ref-1 in cancer and endothelial cells: small-molecule inhibition of the redox function of Ape1. Antioxid Redox Signal. 2008;10(11):1853-1867.

20. Xie K, Wei D, Huang S. Transcriptional anti-angiogenesis therapy of human pancreatic cancer. Cytokine Growth Factor Rev. 2006;17(3): 147-156.

21. Li M, and Wilson DM. Human apurinic/apyrimidinic endonuclease 1. Antioxid Redox Signal. 2014;20(4):678-707.

22. Kelley MR, Georgiadis MM, Fishel ML. APE1/Ref-1 role in redox signaling: translational applications of targeting the redox function of the DNA repair/redox protein APE1/Ref-1. Curr Mol Pharmacol. 2012;5(1):36-53.

23. Al-Safi RI, Odde S, Shabaik Y, Neamati N. Small-molecule inhibitors of APE1 DNA repair function: an overview. Curr Mol Pharmacol. 2012;5(1):14-35.

24. Yang S, Irani K, Heffron SE, Jurnak F, Meyskens FL. Alterations in the expression of the apurinic/apyrimidinic endonuclease-1/redox factor-1 (APE/Ref-1) in human melanoma and identification of the therapeutic potential of resveratrol as an APE/Ref-1 inhibitor. Mol Cancer Ther. 2005;4(12):1923-1935.

25. Shimizu N, Sugimoto K, Tang J, et al. High-performance affinity beads for identifying drug receptors. Nat Biotechnol. 2000;18(8):877-881.

26. Kelley MR, Luo M, Reed A, et al. Functional analysis of novel analogues of E3330 that block the redox signaling activity of the multifunctional AP endonuclease/redox signaling enzyme APE1/Ref-1. Antioxid Redox Signal. 2011;14(8):1387-1401.
27. Nyland RL, Luo M, Kelley MR, Borch RF. Design and synthesis of novel quinone inhibitors targeted to the redox function of apurinic/ apyrimidinic endonuclease 1/redox enhancing factor-1 (Ape1/ref-1). $J$ Med Chem. 2010;53(3):1200-1210.

28. Lin YC, Chitcharoenthum M, Rikihisa Y. Effect of gossypol on spermatozoal lactate dehydrogenase-X (LDH-X) in male rats. Contraception. 1987;36(5):581-592.

29. Le Blanc M, Russo J, Kudelka AP, Smith JA. An in vitro study of inhibitory activity of gossypol, a cottonseed extract, in human carcinoma cell lines. Pharmacol Res. 2002;46(6):551-555.

30. Band V, Hoffer AP, Band H, et al. Antiproliferative effect of gossypol and its optical isomers on human reproductive cancer cell lines. Gynecol Oncol. 1989;32(3):273-277.

31. Tuszynski GP, Cossu G. Differential cytotoxic effect of gossypol on human melanoma, colon carcinoma, and other tissue culture cell lines. Cancer Res. 1984;44(2):768-771.

32. Dodou K, Anderson RJ, Small DA, Groundwater PW. Investigations on gossypol: past and present developments. Expert Opin Investig Drugs. 2005;14(11):1419-1434.

33. Kitada S, Leone M, Sareth S, Zhai D, Reed JC, Pellecchia M. Discovery, characterization, and structure-activity relationships studies of proapoptotic polyphenols targeting B-cell lymphocyte/leukemia-2 proteins. J Med Chem. 2003;46(20):4259-4264.

34. Zhao J, Gao F, Zhang Y, Wei K, Liu Y, Deng X. Bcl2 inhibits abasic site repair by down-regulating APE1 endonuclease activity. $J$ Biol Chem. 2008;283(15):9925-9932.

35. Li M, Vascotto C, Xu S, et al. Human AP endonuclease/redox factor APE1/ref-1 modulates mitochondrial function after oxidative stress by regulating the transcriptional activity of NRF1. Free Radic Biol Med. 2012;53(2):237-248.

36. Li MX, Wang D, Zhong ZY, et al. Targeting truncated APE1 in mitochondria enhances cell survival after oxidative stress. Free Radic Biol Med. 2008;45(5):592-601.

37. Wilson DM, Takeshita M, Demple B. A basic site binding by the human apurinic endonuclease, Ape, and determination of the DNA contact sites. Nucleic Acids Res. 1997;25(5):933-939.

38. Swann MJ, Peel LL, Carrington S, Freeman NJ. Dual-polarization interferometry: an analytical technique to measure changes in protein structure in real time, to determine the stoichiometry of binding events, and to differentiate between specific and nonspecific interactions. Anal Biochem. 2004;329(2):190-198.

39. Karim K, Taylor JD, Cullen DC, Swann MJ, Freeman NJ. Measurement of conformational changes in the structure of transglutaminase on binding calcium ions using optical evanescent dual polarisation interferometry. Anal Chem. 2007;79(8):3023-3031.

40. Chen DS, Herman T, Demple B. Two distinct human DNA diesterases that hydrolyze 3'-blocking deoxyribose fragments from oxidized DNA. Nucleic Acids Res. 1991;19(21):5907-5914.

41. Tell G, Quadrifoglio F, Tiribelli C, Kelley MR. The many functions of APE1/Ref-1: not only a DNA repair enzyme. Antioxid Redox Signal. 2009;11(3):601-620.

42. Vascotto C, Bisetto E, Li M, et al. Knock-in reconstitution studies reveal an unexpected role of Cys-65 in regulating APE1/Ref-1 subcellular trafficking and function. Mol Biol Cell. 2011;22(20):3887-3901.

43. Hu F, Mah K, Teramura DJ. Gossypol effects on cultured normal and malignant melanocytes. In Vitro Cell Dev Biol. 1986;22(10):583-588.

44. Yeow WS, Baras A, Chua A, et al. Gossypol, a phytochemical with BH3-mimetic property, sensitizes cultured thoracic cancer cells to Apo2 ligand/tumor necrosis factor-related apoptosis-inducing ligand. J Thorac Cardiovasc Surg. 2006;132(6):1356-1362.

45. Van Poznak C, Seidman AD, Reidenberg MM, et al. Oral gossypol in the treatment of patients with refractory metastatic breast cancer: a phase I/II clinical trial. Breast Cancer Res Treat. 2001;66(3):239-248.

46. Parsons JL, Dianova II, Dianov GL.APE1 is the major 3'-phosphoglycolate activity in human cell extracts. Nucleic Acids Res. 2004;32(12): 3531-3536. 
47. Vascotto C, Cesaratto L, Zeef LA, et al. Genome-wide analysis and proteomic studies reveal APE1/Ref-1 multifunctional role in mammalian cells. Proteomics. 2009;9(4):1058-1074.

48. Huang YW, Wang LS, Chang HL, et al. Molecular mechanisms of (-)-gossypol-induced apoptosis in human prostate cancer cells. Anticancer Res. 2006;26(3A):1925-1933.

49. Volate SR, Kawasaki BT, Hurt EM, et al. Gossypol induces apoptosis by activating p53 in prostate cancer cells and prostate tumor-initiating cells. Mol Cancer Ther. 2010;9(2):461-470.

50. Sung B, Ravindran J, Prasad S, Pandey MK, Aggarwal BB. Gossypol induces death receptor-5 through activation of the ROS-ERK-CHOP pathway and sensitizes colon cancer cells to TRAIL. J Biol Chem. 2010; 285(46):35418-35427.
51. Wang Y, Lonard DM, Yu Y, Chow DC, Palzkill TG, O'Malley BW. Small molecule inhibition of the steroid receptor coactivators, SRC-3 and SRC-1. Mol Endocrinol. 2011;25(12):2041-2053.

52. Carrero P, Okamoto K, Coumailleau P, O'Brien S, Tanaka H, Poellinger L. Redox-regulated recruitment of the transcriptional coactivators $\mathrm{CREB}$-binding protein and $\mathrm{SRC}-1$ to hypoxia-inducible factor 1 alpha. Mol Cell Biol. 2000;20(1):402-415.

\section{Publish your work in this journal}

Drug Design, Development and Therapy is an international, peerreviewed open-access journal that spans the spectrum of drug design and development through to clinical applications. Clinical outcomes, patient safety, and programs for the development and effective, safe, and sustained use of medicines are a feature of the journal, which has also been accepted for indexing on PubMed Central. The manuscript management system is completely online and includes a very quick and fair peer-review system, which is all easy to use. Visit http://www.dovepress.com/testimonials.php to read real quotes from published authors.

Submit your manuscript here: http://www.dovepress.com/drug-design-development-and-therapy-journal 